\title{
Strategic Plan regarding Qingyang E-commerce Development
}

\author{
Linxi Shi \\ College of Economics and Management, Longdong University, Qingyang, 745000, China \\ E-mail: 403025330@qq.com
}

Keywords: Qingyang; e-commerce; strategic plan

\begin{abstract}
As a novel business operational behavior, e-commerce has been accepted within the society to an increasingly larger extent. Nowadays, the city of Qingyang has already basically formed the market system of e-commerce, and all the seven counties in Qingyang have been listed as the comprehensive demonstration counties in response to the national policy of e-commerce entry into rural areas, and Qingyang has become the first city in Gansu Province that has a full coverage of e-commerce for the poverty counties in China. Furthermore, based on SWOT analysis, prominent problems that currently exist in Qingyang are thoroughly analyzed, such as the shortages of e-commerce technical talents, incompleteness of the comprehensive public service system, restricted good delivery range, insufficient influential power of brands, etc. Therefore, Qingyang urgently needs to gradually enhance the talent training system under the support of government; improve the public service system of e-commerce; build a complete warehouse logistical delivery system; and enhance the brand competitiveness and sales competence for agricultural products. Starting from basis and followed by gradual implementation, a healthy and sustainable growth of e-commerce for Qingyang shall be constantly facilitated.
\end{abstract}

In recent years, Qingyang has been focusing on e-commerce as the significant leverage to accelerate industrial convergence and upgrading as well as the structural reform of supply-side, under the guidance of "facilitated by government, led by corporates, participated by society, accelerated by brand, supported by industry, incubated by caretakers", with the support of "Internet Plus" Mode, the construction of e-commerce platform and service system has been largely promoted, consumption potential of rural areas has been continuously released, the regional economic development has been significantly enhanced to a higher level and stage. The e-commerce industry in Qingyang has achieved rapid development, blooming like flowers in summer, and the popularity of e-commerce applications has been constantly improved, by combination between online and offline services, unprecedented changes have been brought to people's life style and production.

\section{Brief Introduction regarding the E-commerce Development in Qingyang}

Since 2015, Qingyang has been largely leveraging the industrial development of e-commerce for achieving growth in economic transformation, and issued a variety of supportive policies. By constantly improving the constructions of e-commerce administrative system and rural logistic system, a series of supportive polices in terms of entrepreneurship and employment, in order to encourage college graduates and young entrepreneurs to return to their homeland for creating new business; Qingyang has been continuously cultivating multiple rural e-commerce marketing systems, enhancing the level of rural e-commerce applications, and improving the environment for rural e-commerce development, which could further strengthen the constructions of e-commerce administrative system and rural logistic system, and facilitate a healthy development for the industrial chain of agricultural products.

Currently, all the seven counties in Qingyang have been listed as the comprehensive demonstration counties in response to the national policy of e-commerce entry into rural areas, and Qingyang has become the first city in Gansu Province that has a full coverage of e-commerce for 
the poverty counties in China. It has gained the capital of 140 million CNY supported by the national financial sector, and more than 10 million CNY from the Gansu e-commerce capital, as well as 28 million CNY as Qingyang e-commerce supportive capital. Furthermore, e-commerce entrepreneurial incubator of Qingyang has organized e-commerce conference initiated by the Ministry of Commerce, the CPC Central Committee, e-commerce training for Poverty Alleviation Demonstration Project of Poverty Filing and Card Distribution in Qingyang, 2017.

Generally speaking, characteristics of e-commerce development for Qingyang can be described as follows:

(1) The e-commerce industry has achieved continuous development across the city, and the e-commerce trade has been constantly increasing. Until now, the number of logistic companies registered in the city has reached 24, with 386 logistic express stations, and 8 county e-commerce service centers, 116 village e-commerce service centers, which has achieved full coverage, and 991 e-commerce service centers have been built in countryside. Up to the present, the city has completed trainings for more than 30,000 person-time regarding e-commerce, and the total number of professionals working for e-commerce has reached over 30,000. Until then end of 2017, e-commerce service network for the city, county, village, and countryside has basically been formulated, with accumulated e-commerce trade reaching 2.6 billion CNY, and e-commerce industry has already become the new engine of economic development for Qingyang.

(2) The effect of local network platform has been increasingly prominent. The local self-built platform for Qingyang has presented the trend of increasing investment, various operational model, and growth in operational profit. Currently, there are already more than 20 self-built platforms such as Yilong, Baotuan, Bestmayi, Xinbei Mall, Huangtu Youpin, Center of Cultural Specialties, Qingyang Village, Qingyang Search, Lvpaiji, Northwestern Rural Cooperative Network, Longshang Online, Gou Ma, Qingyang Seeding Network, etc.

(3) The popularity of online agricultural products has been gradually improving. Qingyang has been further accelerating the e-commerce brand cultivation within the region, and more than 50 sorts of major products for online sales were selected from more than 300 agricultural and forest specialties and folk cultural products, with in-depth research on the packaging, a series of online sales products have been formed with agricultural products such as apples, day lily, miscellaneous grains, white melon seeds, apricot products, walnuts, millet, etc.; forest products such as black fungus, honey, morchella, etc.; folk cultural products such as sachet, embroidery, paper cutting, shadow puppet, etc., which has effectively facilitated the development of agricultural characteristic development, and employed 80,000 people with poverty into the e-commerce industrial chain, with income of more than $300 \mathrm{CNY}$ for each person. Furthermore, the total sales of agricultural characteristic products in Huan County has reached more than 60,000 orders, with sales revenue exceeding 5 million CNY. Moreover, the company of Maishangke in Huan County has achieved a highest amount of orders that reached 20,000 in a single day. The Qingxin Fruit Company in Qing County together with the e-commerce service station in Fangzhai Village, Xiangle Town, have achieved a total sales of 400 tons of apples through online promotion activities. Additionally, the e-commerce service station in Huijiamiao Village, Tongchuan Town, Qingcheng County has achieved a total annual sales of revenue as high as approximately 200,000 CNY. Moreover, the e-commerce service station of Yulinzi Town, Zhengning County has sold honey in 20 tons through Taobao and Wechat Business, with sales revenue exceeding 1 million CNY. Gansu Yunzhonglai E-commerce Co., Ltd. has joint the promotion of JingDong SecKill, having sold 40000 kilos of apples, ranking the first place in the fresh products of JingDong SecKill across the country.

\section{Analysis of Strategic Environmental Factors for E-commerce Development in Qingyang Based on the SWOT Analysis Method}

\subsection{Analysis on the Current Strengths of E-commerce Development in Qingyang}

First of all, governments of Gansu in all levels have been constantly raising the significance of e-commerce development in rural areas, as well as the investment of fundamental constructions 
regarding Informationization. The government of Qingyang has established the leading team of Qingyang e-commerce instructed by the Vice Mayor in 2015, and implemented by Bureau of Commerce, Technology, Finance, Industry and Commerce, and Transportation, etc. Entrepreneurial incubators were also established in Qingyang specifically for encouraging and supporting college graduates and young entrepreneurs to go back to homeland for starting new business. Moreover, the support of policy is also enormous, specific supportive capital was allocated to assist the logistic system construction, financial system construction, talent cultivation, fundamental infrastructure construction of e-commerce platforms, etc. during the process of rural e-commerce development, in order to build solid foundation for the further development of e-commerce in Qingyang.

Furthermore, the atmosphere of participating in e-commerce development has already been formed. Nowadays, the e-commerce development in Qingyang has triggered a fairly ardent atmosphere, and companies, leaders in breeding and cultivation, college governmental officers, young entrepreneurs have all participated in the e-commerce projects, with a strong market need.

\subsection{Analysis on the Current Weaknesses of E-commerce Development in Qingyang}

First of all, the "drawback" of talent is a significant problem. The duration of e-commerce development in Qingyang is rather short, with only three years of speedy development starting from 2015, and the problem of e-commerce professional shortage is a general concern all over the country. Moreover, the less developed areas in the west is a rather weak region in terms of the e-commerce development, therefore, the problem of talent shortage is more prominent, furthermore, e-commerce is rather new to these less developed areas in the west, with now experiences to refer to, which still needs further and gradual explorations, thus we must address the talent cultivation and experience exploration, and make adjustment during the process of development, and achieved a completely innovative and successful model.

Secondly, the problem of resource dispersion and brand absence is also prominent. The conventional agricultural economy is a dispersed operational model based on the unit of family, the production is not huge with no packaging or brand, and thereby it is difficult to sell products to other areas through the means of the Internet or logistics. Currently, Qingyang only possess few professionalized companies with capabilities of brand promotion, and the joint power has not been formed yet regarding the gathering of agricultural products from a large number of dispersed farmers. Therefore, professional brand promotion companies need to be introduced, with a thorough assembly of the urban resources, a healthy market environment that is suitable for e-commerce development could be formulated.

In addition, the combination of people living in poverty and the e-commerce industrial chain is not sufficient. People living in poverty face numerous difficulties to open online stores due to reasons such as educational degree, thus they could only provide junior products for the e-commerce to increase incomes.

\subsection{Analysis on the Opportunities of E-commerce Development in Qingyang}

Firstly, the total amount of Internet users has been rapidly increasing across China, and the e-commerce trade is continuously growing. According to the "2018 Internet Development Report in China" officially disclosed by the Internet Society of China, until the end of 2017, the total number of Chinese Internet users has reached 772 million. Regarding the online shopping, last year, the trading scale of online shopping market in China has reached 7,180 billion CNY, with a year-on-year growth rate of $32.2 \%$, and the market growth has arrived at the crossroad for further increase. Regarding the online payment, until the end of last year, the total amount of online payment users in China has reached 531 million, which has increased by 56.61 million comparing to the end of 2016, with an annual growth rate of $12.3 \%$. Moreover, the trade of the tird party online payment in 2017 has reached 143, 260 billion CNY, and the trade of online shopping market has reached 5,330 billion CNY, and the trade of online retail market has reached 7,180 billion CNY.

Furthermore, the market potential for rural e-commerce market is enormous. Due to the differentiation of regional resource distribution, the resources for many less developed regions are rare, thereby many Internet users choose the e-commerce to purchase goods, and the rural 
e-commerce has already become an inevitable trend, with fairly rapid development, and farmers have extremely strong needs towards e-commerce, and it is the optimal time now to largely develop the rural e-commerce.

Additionally, Qingyang has focused on the rural e-commerce, as people have seen the promising future of the agricultural development in the city. However, the rural areas have not formed well organized sales systems with a complete mechanism, therefore, it is difficult to circulate the products from dispersal farmers into the general market. Individual farmers are the most fundamental unit for agricultural production in the countryside, and its intrinsic attribute has determined its incapability to rapidly adapt to the constant changes of the agricultural market. Moreover, the reason for such controversy to formulate lies in the severe absence of comprehensive service platforms, instead of the lack of market or needs. Furthermore, the development of rural e-commerce could effectively solve the disconnection between small farmers and the general market, enhance farmers' capabilities in information application, and break the conventional circulation mode for rural commodities. The future for such market is enormous, with not only economic returns, but also significant social returns.

\subsection{Analysis on the Threats of E-commerce Development in Qingyang}

First of all, the ancillary infrastructure services are incomplete. The internet has played a fundamental role in the development of e-commerce. However, there are also some broadband networks that have not been realized in many remote villages, which is a major obstacle to the development of rural e-commerce. Although the three major operators (China Mobile, China Unicom, China Telecom) have also paid massive attention to the huge demand for broadband services in rural area, at present, the broadband coverage in remote rural areas of Qingyang is still in quite low condition because of rather dispersed user distribution and high cost of construction constraints .

Secondly, warehousing and logistics service system is imperfect. At present, the warehousing, logistics and other related enterprises are adopting a strategy that has nothing to do with each other. Because of the asymmetry of logistics resources, there is such a situation--the sound system has been achieved in some towns and villages while it still leaves blank market in others. In these places, logistics and distribution costs are high, with blind spots appearing. Therefore, the establishment of a perfect warehousing and logistics system is essential to us. We should sort out and transform the original logistics so as to achieve a smooth logistics service.

In addition, the development of rural financial system has encountered bottlenecks. In rural areas, the backward financial system has always been a prominent problem restricting the various commercial activities in these regions. And the development of rural e-commerce is no exception. For rural areas, its financial institutions at the township level is quite very single, where the rural credit cooperatives have taken the dominant position. In fact, although Agricultural Bank of China and Postal Saving Bank have set up some operation outlets in villages and towns, the development of related business is rather scarce. There are very few farmers who use the UnionPay card in realizing the payment function. Or even, some farmers do not have credit cards. All these issues have been of great concern to governments at all levels. In the development of e-commerce, financial payment is a link that cannot be ignored. If this issue cannot be properly resolved, then e-commerce cannot be further developed indeed. At the same time, financial problems in rural areas are matters not easy to solve. It is almost impossible to find a method in a short time. Therefore, the introduction of innovative operation mode is imperative in solving the problem of online payment. As a result, a viable solution can be found in this way where external measures are not available.

\section{A Strategic Method to Promote Healthy and Sustainable Development of E-commerce in Qingyang}

According to the internal strengths and weaknesses, external opportunities and threats, I hold the point that the opportunities we face at present are greater than the threats, and our internal strengths outweigh the weaknesses. In the current favorable macro environment, resources should be fully 
integrated. With the strong support of the Qingyang Municipal Government, external threats and internal weaknesses should be gradually addressed. All these should start from the foundation and be implemented one by one. We should step up the implementation of measures while reducing risks. And the result of accomplishing the whole task at one stroke is something we should not expect.

(1) Improve personnel training system. The formulation of e-commerce personnel training program should be speeded up, and the construction of e-commerce personnel training system should be promoted step by step. With the combination of case teaching and experiential training, targeted e-commerce training should be carried out, which is to improve the ability of e-commerce practitioners and farmers in using e-commerce. A sound multi-level training system should be established; the incentive measures for the introduction of e-commerce talents should also be improved. And middle and high-end talents as well as compound talents suitable for the development of e-commerce in Qingyang should be introduced through various channels, with professional electronic commerce technology and management personnel team well formed. As for rural youth, college graduates, homecoming youth, veterans, precision poor households, the conducts of self-employment by means of electronic commerce should also be supported. Similarly, in rural areas, cultural transmission, distance education and technical training for farmers are also matters that need to be further strengthened. Enterprises, cooperatives and other institutions should be encouraged to transform and upgrade with the help of e-commerce. We should not only continue to develop and expand the network business team, but also gradually cultivate a number of local e-commerce talents and e-commerce service enterprises.

(2) Improve the public service system of e-commerce. A multi-functional e-commerce public service center should be built up with no efforts spare out, which integrates the e-commerce consultation, e-commerce training, e-commerce services, commodity trading, online payment, financial services, business incubation, cultural tourism, OTO product experience hall. Through it, we can provide quality public services for the development of e-commerce. In addition, the construction of integrated information service platform should also be strengthened, which is to make the "network available every village and town" become a reality. Besides government affairs, information transmission and e-commerce, platform based revaluation services can also be launched in succession, such as the establishment of rural cultural information service platform with "culture available every village and town", and the rural science and technology information service platform with "science and technology available every village and town", or the some special information service platforms just like rural party building information service with "party building spread every village and town". As a result, the level of culture, education, science and technology as well as party building in rural areas can be comprehensively upgraded, which adapts to the needs of building a new socialist countryside.

(3) Establish and improve warehousing logistics distribution system. After the network communication facilities and technology have been well solved, logistics distribution is a bottleneck restricting the development of e-commerce in some less developed areas such as Qingyang. On the basis of the original logistics resources in the whole region, a sound logistics service system that integrates rural to urban can be established relying on the service system of CATV Township radio \& TV service station and service system of rural power. It includes: storage, refrigeration, transportation dispatch, and short distance transportation. At the specific level, 1 or 2 express logistics and distribution backbone enterprises can be focused on nurturing. For every logistics distribution line, only one logistics company is supported here. With perfect functions, the public storage and distribution center, township-level distribution center, and village-level terminal distribution networks should be established, which are equipped with the functions of cold chain storage, product classification, product packaging and sorting. Also, the urban and rural logistics co delivery system should be carried out. The distribution and operation mode of "ordering online \& taking delivery offline" and "terminal integration" should be promoted. Through interactive communication, it may raise the status of peasants from the "last kilometer " to the place of "the first kilometer", which enables information resources and technology to step smoothly to the 
countryside, the villages and households. So, all the farmers can enjoy this convenience directly. By integrating resources and strengthening team building, the bottleneck problems such as deficient in operation service and logistics distribution, which restrict the process of rural informatization and rural e-commerce, can be solved smoothly.

(4) Enhance the brand strength and sales ability of agricultural products. Based on the characteristics of Qingyang's industrial economy, the multi-dimensional integration of e-commerce and characteristic industries should be vigorously promoted. At the same time, we should speed up the collection of characteristic industries, highlight the advantages of characteristic industrial clusters, build famous e-commerce industry with its own characteristics, establish the traceability system for agricultural products quality, and conduct the certification of product source traceability. Moreover, relying on Qingyang's special agricultural products, the mode of "company + farmer" and "supermarket + base" should be further recommended to vigorously develop the commodity production and expand the two-way double network circulation; Combined with the development of rural informatization, we should guide more farmers to set up online stores. This group of people will be transformed from farmers into netizens or businessmen, so as to enhance the sales ability of agricultural products.

\section{References}

[1] Reporter of China Economic Herald, Xingong, National Development and Reform Commission and Alibaba Group Signed a Strategic Cooperation Agreement on Developing Rural E-commerce in Combination with the Pilot Project of Returning Hometown [N], China Economic Herald, 2016-02-17.

[2] Ministry of Finance, Ministry of Commerce, "E-commerce into the Rural" Comprehensive Demonstration Counties of 2015 (full list), China Electronic Commerce Research Center, July 25, 2015.

[3]Shan Xu, Bin Lyu, Tianzuo Wen, Research on the New Mode of Rural Urbanization and Rural Development based on E-commerce, [J]. International Urban Planning, 2015 (01): 14-21.

[4] Xinglin Du, The "Suichang Mode" of Rural E-commerce, [J]. Policy Lookout, 2015(10):34-37.

[5] China Gansu Net, [EB/OL].http: //www.gansu.gov.cn/art/2015/6/24/ar_35_241407.html.

[6] Jiali Ye, The Current Situation and Problems of E-commerce in China, [J]. Business Economics, 2010 (7): 35-37.

[7] Hui Zhang, The Development Status of E-commerce in China, [J]. China Economy and Trade, 2012 (20).

[8] Wenchuan Huang, Government Promotion of E-commerce, [D]. Party School of the CPC Central Committee, 2006.

[9] Chi He, Tiyun Huang, Yingyan Li, Research on the Logistics System of Agricultural Products Under E-commerce, [J]. Market Theory, 2009 (9).

[10] Yuyan Liu, Development of E-commerce in the Context of New countryside [J]. Science Guide, 2016 (6).

[11] Xiaoling Yang, A Brief Analysis of the Development of E-commerce in Ethnic Areas [J]. Chinese E-commerce, 2011 (4): 28-29.

[12] Fang Lin, Research on New Mode of Rural E-commerce in Hunan [D]. Hunan Agricultural University, 2014.

[13] Xuhua Ge, Research on the Development of Rural Mobile E-commerce in Loudi [D]. Xiangtan University, 2013.

[14] Shixian Li, Research on the Impact of E-commerce Development on Foreign Trade of China 
[D]. Zhejiang University, 2014.

[15] Jing Liu, Research on the development status and Countermeasures of agricultural e-commerce in China [D]. Huazhong Normal University, 2014. 